\title{
CLINICOEPIDEMIOLOGICAL STUDY OF LEPROSY IN A TERTIARY CARE CENTER- A THREE YEAR STUDY
}

\author{
Dhanalakshmi Kasi1, Senthil Ganapathy², Vinothiney Krishnamoorthy33, Sindhuja Balaji ${ }^{4}$
}

${ }^{1}$ Associate Professor, Department of Dermato-Venereo-Leprology, Thanjavur Medical College, Thanjavur, Tamilnadu, India. ${ }^{2}$ Assistant Professor, Department of Dermato-Venereo-Leprology, Thanjavur Medical College, Thanjavur, Tamilnadu, India. ${ }^{3}$ Postgraduate Student, Department of Dermato-Venereo-Leprology, Thanjavur Medical College, Thanjavur, Tamilnadu, India. ${ }^{4}$ Associate Professor, Department of Dermato-Venereo-Leprology, Thanjavur Medical College, Thanjavur, Tamilnadu, India.

\section{ABSTRACT}

\section{BACKGROUND}

Leprosy is a major public health problem in developing countries. India dominates the global picture with $60 \%$ of the world's leprosy cases. This study was done to bring about the current trends in the clinicoepidemiological profile of leprosy in a tertiary care center.

The aim of this study was to evaluate the epidemiological and clinical profile of leprosy patients in a tertiary care center.

\section{MATERIALS AND METHODS}

This is a descriptive study of all patients who attended Urban Leprosy Clinic (ULC) in the department of Dermato-Venereology during the period from January 2014-2017. Leprosy patients seen during this period were registered at the ULC and the records were maintained by a health inspector posted at the department, under the supervision and guidance of the consultants in the department. Clinical spectrum of the patient was determined obtaining detailed clinical history and meticulous clinical examination followed by slit skin smear examination and histopathological evaluation. All the patients were treated with paucibacillary and multibacillary drug therapy according to their disease spectrum.

\section{RESULTS}

A total of 214 patients attended the Urban Leprosy Clinic during the year January 2015- December 2017 in our hospital.

\section{CONCLUSION}

Notable thing in our study is high new case detection rate despite the reduction in prevalence rate. Lack of awareness about the disease in the community might be the cause for the delay in reporting and hence a late diagnosis resulting in majority of patients fall under multibacillary spectrum.

\section{KEY WORDS}

Leprosy, Epidemiology, Clinical Profile.

HOW TO CITE THIS ARTICLE: Kasi D, Ganapathy S, Krishnamoorthy V, et al. Clinicoepidemiological study of leprosy in a tertiary care center- a three year study. J. Evolution Med. Dent. Sci. 2019;8(07):454-457, DOI: 10.14260/jemds/2019/100

\section{BACKGROUND}

Knowledge and understanding of epidemiological profile are essential pre-requisites to access and address public health needs in a country and to enable efficient programme and management. Leprosy is a chronic infectious and granulomatous disease caused by Mycobacterium leprae primarily affecting peripheral nerves and skin and secondarily affecting other organs presenting with different clinicopathological forms.

An impressive decline in leprosy prevalence rate in all endemic districts of India is seen in the post-multidrug therapy era. However, the new case detection rate, an important statistical indicator in leprosy control program has not shown significant decline in spite of all efforts. India contributes about $80 \%$ of the global leprosy case load.

'Financial or Other Competing Interest': None.

Submission 21-09-2018, Peer Review 30-01-2019,

Acceptance 09-02-2019, Published 18-02-2019.

Corresponding Author:

Senthil Ganapathy,

AA-23, Thangam Nagar,

MC-Road, Thanjavur,

Tamilnadu

India.

E-mail: drsenthilganapathy@gmail.com

DOI: $10.14260 /$ jemds $/ 2019 / 100$
A total of 1.25 lakh new cases were detected during the year 2015-2017 which gives annual case detection rate of 9.73 per 100, 000 population. This shows annual new case detection rate reduction by $2.5 \%$ from $9.98 \%$ during 2014 2015. A total of 88, 833 lakh cases were on record as on $1^{\text {st }}$ April 2016 giving a prevalence rate of $0.69 / 10,000$ on $31^{\text {st }}$ December 2005.

It is true that a full course of multi-drug therapy (MDT) makes leprosy cases non-infectious but that does not have any significance in occurrence of new cases. Hence new case detection rate is a more significant parameter to estimate the leprosy than prevalence rate. This retrospective study was carried out to find the epidemiological and clinical trends of leprosy in a tertiary care hospital.

\section{MATERIALS AND METHODS}

The descriptive study of all the patients who attended the Urban Leprosy Clinic in the department of Dermato-VenereoLeprology/during this period from January 2015-2017 were evaluated. The leprosy patients during this period were registered at the urban leprosy clinic and the records were maintained by a health inspector posted at the department, under supervision and guidance of the consultants in the department. Clinical spectrum of the patient was determined after eliciting detailed clinical history, clinical examination, slit skin smear examination and histopathological evaluation. 
All the patients were treated with paucibacillary and multibacillary multi-drug therapy depending upon the disease spectrum.

\section{RESULTS}

A total of 214 patients attended the Urban Leprosy Clinic during the year January 2015- December 2017 in our hospital.

\section{Demographic Characteristics}

Among 214 patients attended the clinic, 152 were males, 62 were females.

Males outnumbered females with a ratio of 2.4:1. Majority of patients were in age group $16-40$ yrs. $-60.2 \%$ followed by $>40$ yrs. $-26.1 \%$ and then $<15$ yrs. $-13.5 \%$. The patients themselves presented with different clinical Morphology. Borderline tuberculoid Hansen's disease -

- $44.8 \%$, borderline lepromatous Hansen's disease.

- $15.8 \%$, Lepromatous leprosy-11.2\%, pure neuritic leprosy.

- $5 \%$, tuberculoid leprosy- $10.2 \%$, indeterminate leprosy.

- $1 \%$, mid-borderline leprosy- $11.2 \%$.

\begin{tabular}{|c|c|c|c|}
\hline Year & Up to 15 Years & 15-40 Years & >40 Years \\
\hline 2015 & 7 & 43 & 27 \\
\hline 2016 & 11 & 42 & 19 \\
\hline 2017 & 11 & 44 & 10 \\
\hline \multicolumn{3}{|c|}{ Table 1. Age Specific Distribution of Cases } \\
\hline
\end{tabular}

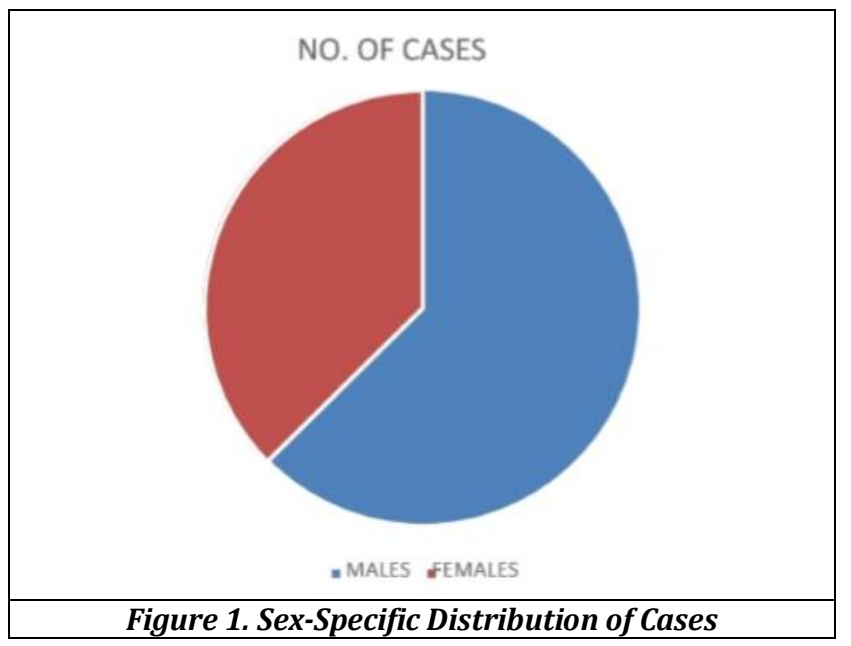

\begin{tabular}{|c|c|c|c|c|}
\hline & \multicolumn{2}{|c|}{ Paucibacillary } & \multicolumn{2}{c|}{ Multibacillary } \\
\hline Year & Adults & Children & Adults & Children \\
\hline 2015 & 19 & 4 & 51 & 3 \\
\hline 2016 & 20 & 8 & 41 & 3 \\
\hline 2017 & 14 & 8 & 40 & 3 \\
\hline \multicolumn{3}{|c|}{ Table 2. Spectrum Among Various Patients } \\
\hline
\end{tabular}

\begin{tabular}{|c|c|}
\hline Disease Spectrum & No. of Cases \\
\hline Indeterminate & 3 \\
\hline Borderline Tuberculoid & 96 \\
\hline Tuberculoid & 22 \\
\hline Mid borderline & 24 \\
\hline Borderline Lepromatous & 34 \\
\hline Lepromatous Leprosy & 24 \\
\hline Pure Neuritic & 11 \\
\hline Table 3. Clinical Disease Spectrum Among Various Patients \\
\hline
\end{tabular}

\begin{tabular}{|c|c|}
\hline Deformities & No. of Cases \\
\hline Claw Hand & 23 \\
\hline Foot Drop & 11 \\
\hline No deformity & 180 \\
\hline \multicolumn{2}{|c|}{ Table 4. Deformities } \\
\hline
\end{tabular}

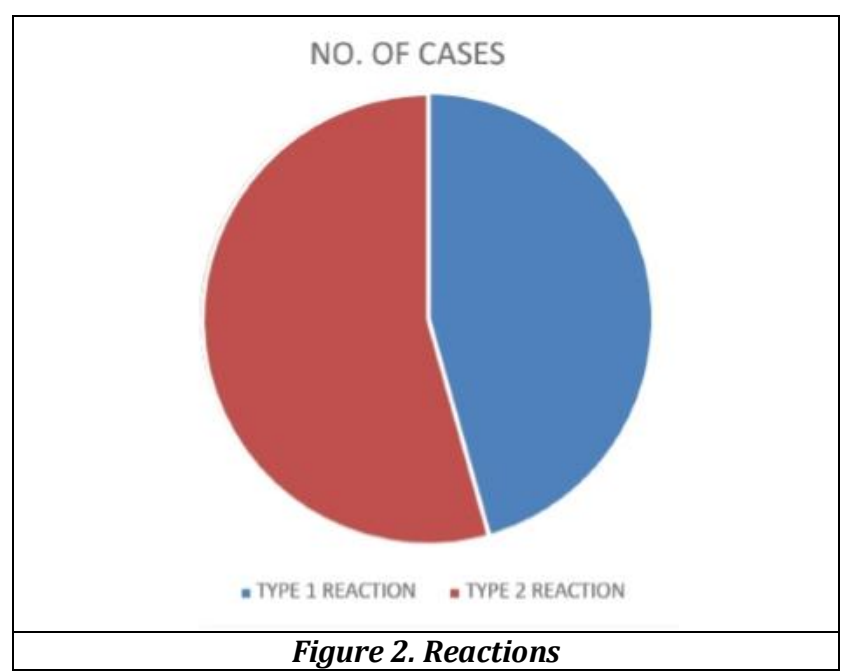

Clinical Disease Spectrum Among Data Analysis

Borderline tuberculoid leprosy was responsible for maximum disease load in our patients with $44.8 \%$ followed by borderline lepromatous leprosy with $15.8 \%$, lepromatous leprosy \& mid-borderline with $11.2 \%$ each, tuberculoid type with $10.2 \%$, pure neuritic leprosy with $5 \%$, indeterminate type with $1 \%$.

\section{Reactions \& Deformities}

$14.4 \%$ of patients presented with type 1 reactions, $16.3 \%$ of patients presented with type 2 reactions. $15.8 \%$ patients presented with deformities. $294 \%$ of patients had peripheral nerve thickening $11.8 \%$ had trophic ulcer, $5.9 \%$ had weakness, 53\% had oedema, 3.5\% had ichthyosis.

\section{Management}

Diagnosis was made on the basis of clinical, slit skin smear examination and histopathological evaluation of the patients. Patients were given paucibacillary and multi bacillary multidrug treatment according to WHO guidelines. 85\% were started on MDT -MB, $14.1 \%$ were on PB -MDT, 1\% relapse. Management of deformities was done according to grade and type of deformity. Thick calluses were removed, proper wound care and dressing of ulcers if present was done. Physiotherapy for mobile flexion deformity was provided by physiotherapy department and appropriate patients were referred for corrective surgeries.

\section{DISCUSSION}

The worldwide introduction of MDT has cured millions of leprosy patients. In India, a country with largest case load, MDT has brought down the prevalence of disease from 25.9 in 1991 to less than 1/10000 population in March 2009.The elimination of disease has been achieved at national and state level in many states.(1) The infrastructure has been developed to provide MDT services to control leprosy. The implementation of MDT program has helped in updating registers and improving case management in such a way that a substantial reduction in prevalence has been achieved in all 
leprosy endemic states/countries. Despite noticeable decrease in prevalence rate, the annual new case detection rate has not declined so steeply. Once a leprosy patient completes a full course of treatment, he/she is no longer registered as a leprosy patient even though there are residual disabilities. Thus, when only a shorter time period qualifies for the term leprosy patient the numbers of registered patients will be automatically decreased.(2)

At the national level also MB ratio has increased from $25.9 \%$ in 1994 to $48.4 \%$ in 2008-09.(2,3) The possible reason for this could be.(4) In contrast to active search wherein cases are detected early, voluntary reporting to health facility occurs late when the disease is relatively advanced as the patients were not well aware of the disease. This is more likely to be in poorer sections. This can be the explanation of high MB cases in our hospital where $85 \%$ of patients were of MB type. Many people are far off and seek medical attention only in the late disease process.

The cases are not confirmed or diagnosed early resulting in late registration of cases whereby the disease spectrum turns out to be multibacillary type thus increasing the ratio of MB cases. Since leprosy detection has been shifted from trained experienced workers of vertical to primary health care workers where understanding of leprosy and diagnostic skills may not be as good, this could well have been the reason for sudden decline in PR observed since 1997 and thus sharper decline in PR from 10.9 in 1994 to less than 1/10000 population in December 2005.

Over-zealous attempt to achieve elimination of leprosy at all levels and pressure to eliminate disease by stipulated date would have resulted in non-registering of early cases, resulting in same effect. In our study majority of the patients were in the age group ranging from 16 to $40 \mathrm{yrs}$. with males outnumbering females in the ratio of $2.4: 1$, this is because in India males frequently self-report for treatment. Majority of patients in our study belong to multibacillary spectrum. The type of leprosy commonly present was borderline tuberculoid Hansen's disease followed by borderline lepromatous spectrum, this is in contrast to other studies which shows borderline tuberculoid followed by true tuberculoid to be commonest spectrum.(5) The slums, adjoining major urban areas with illiteracy, poverty, overcrowding and unhygienic conditions proving to be fresh focus for leprosy transmission. (4)

Large number of new cases have been detected in recent years because of the adoption of modified leprosy elimination campaign (MLEC) and effective health education campaign.(6) The most important factor that could have significant impact on prevalence is the coverage of the entire population with adequate multidrug therapy.(7,8) These changes indicate early detection of cases due to better awareness in the community about the disease.(9)

Also, disease severity and subsequent reactions and deformities have declined significantly with the advent of multidrug therapy and proper referral to tertiary care hospital. Enhanced global strategy for further reducing the disease burden (2011-2015) has many indicators, such as those for monitoring progress; case detection and patient management as a target. Targets should have epidemiological and operational considerations. These targets should also provide accountability and enable program planning. A key feature of the target is that it must have been obtained by consensus, and be owned by the community and populations concerned. In addition, a target should be evidence based, realistic, attainable, reasonable, measurable and valid, and linked to implementation.

WHO expert committee on leprosy, a body of internationally recognized experts, in its eighth report, recommended a target of incidence of new cases with grade 2 disabilities or visible deformities among new cases to less than one case per million population by the year 2020 .

There are certain major challenges being faced by our community in reducing the disease burden which includes removing sense of complacency that seems to have set in control programs after initial success, referral systems are weak in most of the endemic countries, developing effective tools/tests to detect cases early, including tools/tests for early recognition and management of leprosy reactions, there are much needs to be done in the field of prevention of disabilities and rehabilitation, improving information, education and communication components of the program to be locally relevant, cost effective and sustainable, problem in accessing three major endemic countries, developing alternative treatment regimens to combat the threat of drug resistance, developing effective vaccines for the prevention of leprosy.

Rising awareness to focus on initiating response to early symptoms of leprosy and covering persons and population groups at risk of developing leprosy is the need of the hour in leprosy control.

In the area of stigma reduction and developing community-based initiatives, inputs on stigma reduction and enhancing participation of people affected will be sought from the organizations with necessary expertise, so that, it would be appropriately included in the next global strategy covering the period from 2016-2020.

\section{CONCLUSION}

Adequate information is available on the pathogen, methods of detection, some epidemiological factors, MDT as the best therapy so far, second line drugs, methods to prevent and manage deformities and reactions, methods for diagnosis of leprosy at a field level. Further knowledge on simpler methods of early diagnosis, molecular aspects of Mycobacterium leprae, extra-human reservoirs, would be helpful. However, translation of existing knowledge has been poor and meagre, and if done seriously, would suffice to promote early detection and prompt effective antileprosy therapy and control of reactions.(10)

Notable thing in our study is high new case detection rate despite the reduction in prevalence rate. Lack of awareness about the disease in the community might be the cause for delay in reporting and hence a late diagnosis resulting in majority of patients falling under multibacillary spectrum.

\section{REFERENCES}

[1] Kumar A, Girdhar BK. Is increasing MB ratio a positive indicator of declining leprosy? J Commun Dis 2006;38(1):24-31.

[2] Harboe M. Leprosy at a turning point? Int J Lepr Other Mycobact Dis 2000;68(3):312-8.

[3] Lobo D. Leprosy situation in South-East Asia region. J Commun Dis 2006;38(1):1-6. 
[4] Dambalkar K, Vashist RP, Ramesh V. Problems due to migration of leprosy patients into urban areas. Lepr Rev 1995;66(4):326-8.

[5] NLEP. Progress report for the year 2008-2009 ending on March 2009. Central Leprosy Division, Director General of Health Services Govt. of India, New Delhi. 2009.

[6] Mahajan VK, Sharma NL, Rana P, et al. Trends in detection of new leprosy cases at two centres in Himachal Pradesh, India: a ten-year study. Indian J Lepr 2003;75(1):17-24.
[7] Mandal BC. Present Leprosy situation in India and the decade long experience of this correspondent. Nihon Hansenbyo Gakkai Zasshi 2001;70(1):25-9.

[8] Murthy PK. Current epidemiology of leprosy. J Indian Med Assoc 2004;102(12):672-3, 683.

[9] Pardillo FE, Fajrado TT, Abalos RM, et al. Methods for the classification of leprosy for treatment purposes. Clin Infect Dis 2007;44(8):1096-9.

[10] Kuipers P, Rao PS, Raju MS, et al. A conceptual protocol for translational research in the complex reality of leprosy. Lepr Rev 2013;84(2):166-74. 